\title{
Development of a Model Hospital-based Cancer Registry Database for Better Healthcare Reporting
}

\section{R. K. Sinha MS-MTDM}

Associate Professor

Department of Health Information Management

Manipal College of Allied Health Sciences

Manipal University

Manipal - 576 104,

Karnataka

India

E-mail address: rajesh.sinha@manipal.edu

\section{Saha MBA}

Assistant Professor

Department of Health Information Management

Manipal College of Allied Health Sciences

Manipal University

Manipal - 576104

Karnataka

India

E-mail address: dola.saha@ manipal.edu

\section{P. D'Souza MSc. HHIA}

Department of Health Information Management, Manipal College of Allied Health Sciences, Manipal University

Manipal - 576104

Karnataka

India

Sri Lanka Journal of Bio-Medical Informatics 2010;1(3):179-185

DOI: 10.4038/sljbmi.v1i3.1889

\begin{abstract}
Hospital based cancer registries work with the objective to support healthcare professionals and managers at all level with complete, accurate and adequate information for treatment planning, epidemiological investigations, prevention and control of cancer. This paper deals with the design, development and implementation of a computerized hospital based cancer registry database to assist the healthcare providers with a simplified solution in easy documentation and instant access of health information of patients with cancer for care planning, research, education, and national cancer registry reporting.
\end{abstract}

Keywords: Hospital Based Cancer Registry, Database, Cancer, National Cancer Registry

Sri Lanka Journal of Bio-Medical Informatics 2010;1(3):179-185

DOI: 10.4038/sljbmi.v1i3.1889 


\section{Introduction}

Cancer is a leading cause of death worldwide, it accounted for 7.4 million deaths; around $13 \%$ of all deaths in 2004. It can be reduced and controlled by implementing evidence-based strategies for cancer prevention, early detection of cancer and management of patients with cancer $^{(1)}$ and it is only possible when population and institution-wide information related to cancer is made available to healthcare professionals and decision makers.

Cancer Registry programs play a vital role in providing information to the end users about patient care and disease. Cancer registry program can be broadly categorized into populationbased and hospital-based. Its primary function is to maintain the files or registers of all cancer cases, analyze and interpret the data periodically, and provide information about incidence and prevalence of cancer in a defined population. Such information is not only the source for epidemiological research but is also used for prevention, diagnosis and treatment of cancer ${ }^{(2)}$.

Hospital-based cancer registries aim at improving cancer therapy. Therefore, it is necessary to collect detailed data about diagnosis, therapy, and follow-up ${ }^{(3)}$. Many challenges impede the management of hospital-based cancer registry programs. They include timely collection of patient data, instant access and reporting, dissemination of information to the end users whenever and wherever required.

A computerized cancer registry program provides a new dimension of support for patient care, hospital administration, policy making and research. It supports healthcare professionals to manage a large set of structured data, and run operations in the data requested by numerous users. It reduces the reporting cost and boosts the value of research data. It even guarantees the patient his/her lifetime medical contact about the diagnosis, facilities, follow-up etc. and allows the healthcare professionals to maintain continuing and medically relevant contact with patients.

This need led to the development of this Hospital-based Cancer Registry Database Management System.

\section{Methodology}

The design and development of this cancer registry database was conducted in four phases:

Phase 1 included the identification of clinicians' and hospitals' expectations from the proposed system for documentation, access and reporting of patient data to national cancer registry office. A survey was conducted and the result showed that clinicians and hospitals required a simple, easy to use, and user friendly software where they can generate customized report for patient care, referral and reporting. A related literature search was also conducted to identify the available systems in India and globally. It is evident from the literature search that there are many cancer registry systems available, but works of interest in this case were IMPAC ${ }^{(4)}$, SEER*Stat ${ }^{(5)}$, Kentuchy Cancer Registry ${ }^{(6)}$, Merseyside and Cheshire cancer registry ${ }^{(7)}$, Registry Plus ${ }^{(8)}$, NCRP India ${ }^{(9)}$, RCC cancer registry ${ }^{(10)}$, Oncostudio ${ }^{(11)}$, and CNExT Registry ${ }^{(12)}$. 
The features identified with the above available systems are listed below:

\begin{tabular}{|c|c|}
\hline Systems & Features \\
\hline $\operatorname{IMPAC}^{(4)}$ & $\begin{array}{l}\text { ELEKT A IMPAC meets the regulatory reporting requirements and provides } \\
\text { ready access to the data required to effectively review, analyze, and } \\
\text { ultimately improve clinical outcomes. The system expedites case finding and } \\
\text { improves accuracy and consistency of diagnosis and staging data. }\end{array}$ \\
\hline SEER * Stat $^{(5)}$ & $\begin{array}{l}\text { The SEER*Stat is a statistical software provides convenient and intuitive } \\
\text { mechanism to view and analyze SEER and other cancer related database to } \\
\text { understand the impact of cancer in population. It consists of Boolean logic to } \\
\text { handle complex selection. The reporting results are supported by multi- } \\
\text { dimension matrices. }\end{array}$ \\
\hline $\begin{array}{l}\text { Kentucky } \\
\text { cancer } \\
\text { registry }^{(6)}\end{array}$ & $\begin{array}{l}\text { Kentucky Cancer Registry uses Cancer Patient Data Management System } \\
\text { (CPDMS.net) which is a web based application with interactive, full featured } \\
\text { and user friendly data entry system and consist of a set of pre-defined and } \\
\text { ad-hoc reporting capabilities, ad-hoc queries and built-in analytic functions } \\
\text { such as descriptive statistics, data list's, survival analysis, comparative } \\
\text { analysis and disease free interval analysis. }\end{array}$ \\
\hline $\begin{array}{l}\text { Merseyside \& } \\
\text { Cheshire } \\
\text { cancer } \\
\text { registry }{ }^{(7)}\end{array}$ & $\begin{array}{l}\text { Somerset Cancer Register (SCR) is a single database application designed to } \\
\text { be used as a tool to collect clinical cancer data for each cancer site that } \\
\text { allows real time collection of data in a timely and user friendly way and } \\
\text { assist in the diagnosis and management of the patient with cancer. }\end{array}$ \\
\hline $\begin{array}{l}\text { Registry } \\
\text { Plus } \\
\left({ }^{(8)}\right.\end{array}$ & $\begin{array}{l}\text { Registry Plus assists the end user for collecting and processing cancer } \\
\text { registry data. It can be used separately or together for routine or special data } \\
\text { collection. These software programs, compliant with national standards and } \\
\text { are made available by CDC to implement the National Program of Cancer } \\
\text { Registries. }\end{array}$ \\
\hline NCRP India ${ }^{(9)}$ & $\begin{array}{l}\text { National Cancer Registry Database is a web enabled software assist the end } \\
\text { users to records hospital based and population based cancer data. It also } \\
\text { provides a hospital based online quality control system and assist the user in } \\
\text { generating various hospital based cancer registry report. }\end{array}$ \\
\hline $\begin{array}{l}\text { RCC cancer } \\
\text { registry }^{(10)}\end{array}$ & $\begin{array}{l}\text { RCC Cancer Registry has fully computerized online data entry and search } \\
\text { based Hospital and Population Based Cancer registry database to collect, } \\
\text { analyze and interpret cancer related data available on intranet. }\end{array}$ \\
\hline Oncostudio $^{(11)}$ & $\begin{array}{l}\text { Oncostudio is software tool to manage cancer registry and consist of all the } \\
\text { fundamental variables in a cancer registry such as custom reporting and } \\
\text { exporting filtered data; produce visual output of analysis of cancer data; } \\
\text { calculate frequency distribution tables of cancer grouped by ICD. }\end{array}$ \\
\hline $\begin{array}{l}\text { CNExT } \\
\text { Registry }\end{array}$ & $\begin{array}{l}\text { CNExT Registry provides a power and flexible cancer registry tool for } \\
\text { hospitals and independent registrars. Its Standard Registry and State } \\
\text { Reporting Package consist of strategy-based follow-up system, designed } \\
\text { with input from registrars to automate the monthly follow-up process as } \\
\text { much as possible. }\end{array}$ \\
\hline
\end{tabular}

Phase 2 included the design of model and work flow, where the content of the modules were identified to incorporate them into the system.

Phase 3 where the implantation of the model was completed. The front end was designed using Visual Basic and MS-Access was the backend. The system was designed in such a way 
that the application can work in any environment and operating system.

Phase 4 included the testing of the software; where testing was done based on unit, data structure, functionality, robustness, acceptance, integration and validation.

\section{System Design and Architecture}

Cancer registry database consist of four important modules to assist the clinician in easy documentation and access of patient information as well as in generating various statistical reports for national cancer registry program reporting. The important modules and their features are as follows:

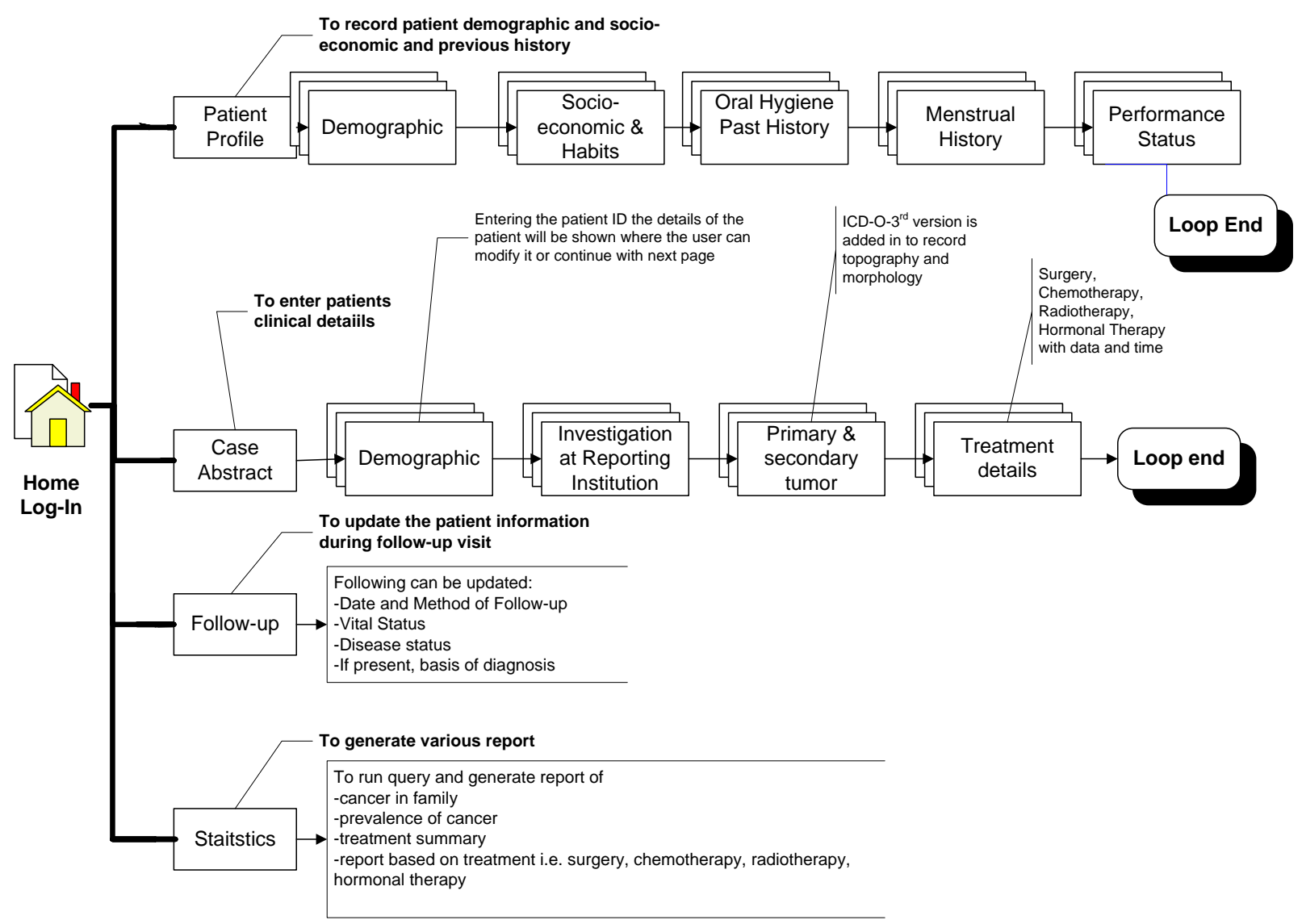

Figure 1. Modules and Work Flow of Cancer Registry System

Patient profile allows for easy documentation of patient details such as demographic and socio-economic characteristics of the patient, oral hygiene, food and other habits, details of previous investigation done; disease status and co-morbidity, details about site and types of tumor (if diagnosed before reporting to the hospital); evidence of disease and its laterality and menstrual history.

Case Abstract supports viewing the demographic details of the patient and recording and access of referral details (if any), physical examination and Investigation done at reporting institution, disease current status with co-morbidity, site or types of tumor (based on investigation result at reporting institution), treatment objectives, treatment received such as details of surgery, chemotherapy, and hormonal therapy. 
International Classification of Disease for Oncology, $3^{\text {rd }}$ version was incorporated into both the above modules to assist the clinician in easy documentation of the site of the tumor (primary and secondary) with topographical and morphological diagnosis.

Follow-up module assists the clinician to record the events of care during follow-up visits such as method of follow-up, disease status (where end user can document the evidence of disease), related investigation results and vital status of the patient.

Statistics module allows the clinician to run various queries and generate reports for patient care, National Cancer Registry reporting, administrative and research purposes. The reports that can be generated using the module are: family history of cancer, prevalence of cancer based on region (district, state and country), religion, age, gender, occupation, and education. The module also allow the end user to view the incidence and prevalence of cancer in various combinations such as lung cancer and smoking or oral cancer and smoking or oral cancer and alcohol, etc. The module also has a free text search to allow the user to view the information by passing the text into the text box. The summary of the treatment can also be generated with the treatment details i.e. surgery, chemotherapy, radiotherapy and hormonal therapy.

\section{System Testing}

The database was tested before the implementation into actual practice. The following test $\mathrm{s}$ were conducted to identify errors in programming and modules if any:

Unit test was conducted to check each module separately to uncover errors in coding, flow of information and link with the other modules. Data structure test was conducted to ensure that the records are saved properly into the database. This was done by entering more than 100 patient records into the system. Functionality test was conducted to determine whether display screen meets the design rules completely and correctly. Robustness test was conducted to study the behavior of modules in case of feeding relevant input to ensure that the system is able to display the appropriate message and back in the initial stage. As for example, if users do a wrong entry into the system, a message will automatically pop-up onto the desktop to alert them regarding error and provide suggestion for the correct entry. Acceptance testing was conducted to verify the readiness for implementation and use. A top down integration test with an incremental approach was conducted with real patient data to test the top integrated module and its branch to isolate and correct errors, as a result the outputs were found to be good. A Validation test was also done to identify the missing data, invalid values, comparison of stored data, and validity of the size of the items.

\section{Access and Security of the System}

To achieve the prime security of the database, the accessibility of the information was restricted based on the group of the user and their uses such as Doctors, Medico-Social Workers and Clerks. As the Medico Social Worker is responsible for collecting demographic and socio-demographic details of the patient, they are provided with access to the sociodemographic page of the patient profile module to enter the respective details during the first visit of the patient. Doctors are allowed to view and enter all the clinical and treatment details by accessing the patient profile, case abstract and follow-up module. Doctors and Clerks are provided with the access to the statistics module to generate various reports for referral and reporting purposes. 
Each user is provided with a unique authentication ticket in terms of ID and Password. Only authorized user with appropriate and correct authentication ticket will have access to the system. The log-in to the system is achieved through passing authentication ticket and once it gets authenticated by the system the user will get access to their respective module.

\section{Features Included for Better Management and Reporting of Cancer Data}

Instead of free text, this system allow a menu driven data entry for most of the parameters to reduce the end user time in recording and management of patient information. Database provides a list of value for each parameter to record patient demographic and clinical details. This feature improves the quality of data by restricting the user to do any mistake during the data entry time. The follow-up updates and performance status of the patient can be captured easily as per World Health Organization performance status scale. The system also allows the clinician to create customized report for the national cancer registry reporting and planning for treatment.

\section{Conclusion}

Cancer registry is often considered as an integral part of hospital cancer care program and healthcare care delivery system. The reports generated from the registry supports the healthcare professionals, administrators, managers and health authority to prevent and control the incidence and prevalence of cancer in the community. Computerized hospital based cancer database provides a central data warehouse where the data can be stored and used whenever and wherever required by the end users. This user friendly system will not only reduce the clinician time in documentation and access of patient information but will also be very effective in generating customized report for submission to national cancer registry office and other third party reporting.

\section{Further Scope of Research}

As the system is not implemented in practice, further research should be conducted to assess the acceptability and sustainability of the system into practice.

\section{References:}

1. Cancer. World Health Organization. February 2009 [Fact Sheet No. 297] [Cited 2010 May 3]; Available from URL: http://www.who.int/mediacentre/factsheets/fs297/en/

2. O.M. Jensen, D.M. Parkin, R. MacLennan, C.S. Muir and R.G. Skeet. Cancer Registration Principle and Method. IARC Scientific Publication No.95. [Cited 2010 May 3]; Available from URL. http://www.iarc.fr/en/publications/pdfsonline/epi/sp95/index.php

3. Cancer Registry: Wikipedia. [Cited 2010 May 3]; Available from URL. http://en.wikipedia.org/wiki/Cancer_registry

4. ELECTA IMPAC Software: managing the spectrum of cancer care. [Cited 2010 May 3]; Available from URL. http://www.elekta.com/healthcare_international_cancer_registry_software.php 
5. SEER*Stat: Version 6.6.2. [Cited 2010 May 3]; Available from URL. http://seer.cancer.gov/seerstat/

6. Cancer Patient Data Management System of Kentucky cancer registry. [Cited 2010 May 3]; Available from URL. www.kcr.uky.edu

7. $\quad$ Somerset Cancer Register. [Cited 2010 May 3]; Available from URL. http://www.mccn.nhs.uk/professionals/intelligence/scr.php

8. Registry Plus: software program for cancer registry. [Cited 2010 May 3]; Available from URL. http://www.cdc.gov/cancer/npcr/tools/

9. National cancer registry program in India. [Cited 2010 May 3]; Available from URL. http://www.ncrpindia.org/

10. Java based cancer registry system. [Cited 2010 May 3]; Available from URL. http://www.rcctvm.org/ISD.htm

11. Oncostudio. [Cited 2010 May 3]; Available from URL: http://www.eng.oncostudio.com/

12. CNExT Registry. [Cited 2010 May 3]; Available from URL. http:/www.askcnet.org/registry.html 